\title{
Circular Waveguide Polarizer for Weather Radars and Satellite Information Systems
}

\author{
Stepan Piltyay \\ Department of Radio Engineering, National Technical University of Ukraine \\ Igor Sikorsky Kyiv Polytechnic Institute, 37, Peremohy Ave., Kyiv,Ukraine, crosspolar@ukr.net
}

\begin{abstract}
This research presents the design and main electromagnetic characteristics of the novel compact microwave waveguide polarizer. The developed device's structure is based on a circular waveguide and anti-phase conducting posts located in it. The application of a circular waveguide instead of a square one allowed simple integration of a polarizer with corrugated horn antennas. The obtaining of required phase difference using a postsbased design provides the possibility of fine tuning of the developed circular waveguide polarizer after its manufacturing process. In addition, simultaneous adaptive operation at orthogonal circular and linear polarizations is available in the antenna system including a polarizer with posts. An automatic control of posts height must be applied in a waveguide in order to provide this option. Numerical simulation, optimization, manufacture and measurements of the polarizer's characteristics were carried out in the operating band 7.4-8.5 GHz. Measured characteristics proved that the suggested circular waveguide polarizer provides good matching and polarization performance. Developed circular waveguide polarizer can be integrated in corrugated horn antenna systems and applied in modern weather radars and satellite information systems.
\end{abstract}

Index Terms - Microwave devices, waveguide components, polarization, waveguide polarizer, weather radar, satellite information systems.

\section{INTRODUCTION}

Electromagnetic waves can possess various types of polarizations [1]. Elliptical polarization is the most common type and it is encountered most frequently in different radio links, systems and antennas. Peculiar types of the polarization are linear and circular ones. Signals, which are carried by the electromagnetic waves with orthogonal linear or circular polarizations, allow to double the volumes of transmitted information in telecommunication and other systems [2]. In addition, the simultaneous analysis of signals with linear and circular polarizations in $\mathrm{C}$ - and $\mathrm{X}$-bands is widely applied for weather forecasts, surveillance and radiolocation in modern airborne radars [3]-[7].

In order to receive, process and transmit to isolated channels the signals with orthogonal polarizations a specific types of modern antennas and microwave devices for their feeding are utilized [8]-[18]. The separation of signals with perpendicular linear polarizations is carried out using orthomode transducers [19]-[23] in such antenna systems. Orthomode transducers are developed based on the waveguide turnstile junctions [19], [20], on the ridged waveguides and structures [9][12], [21], [22] and on the folded Boifot transitions [19], [23]. If the developed dual-polarized antenna 
Journal of Microwaves, Optoelectronics and Electromagnetic Applications, Vol. 20, No. 3, September 2021

DOI: http://dx.doi.org/10.1590/2179-10742021v20i31183

systems requires the possibility of simulation operation within two separate frequency bands, then one must apply an orthomode transducers based on sectoral coaxial ridged waveguides [24]-[29] and coaxial quad-ridged waveguides [30]-[32].

The best antenna option for the reception/transmission of dual-polarized signals with low cross polarization distortions and effective radiation characteristics is the corrugated horn [8], [33]-[45]. Corrugated horns are commonly designed and manufactured based on the cylindrical conical structures. Consequently, their output waveguide is a circular cylindrical one. The simplest way of connection of a corrugated horn to the feeding network is to develop the polarization processing devices based on the same circular cylindrical waveguide. In this case we obtain more compact design without the need of application of additional circular-to-square waveguide transitions [13]-[15]. This is an advantageous solution for airborne and space systems, which always require low weight and dimensions of the applied devices.

A waveguide polarizer is the essential device of the polarization processing unit of dual-polarized antenna systems [13]-[15]. It transforms the polarization type of waves from circular to linear one in the receiving mode or vice versa in the transmitting mode [46]. The application of a circular waveguide makes the whole feed network design more compact, which results in more light and simple structure. There are three main types of the most commonly used discontinuities for the development of waveguide components, namely, there are irises [46]-[57] (or corrugations [58]-[62]), metal posts [63]-[70] and septum plates [17]-[19], [71]-[77]. Besides, a combination of the posts and irises in a single waveguide sections have been recently suggested for the development of new microwave devices [78]-[80]. Waveguide components based on mentioned types of discontinuities are well investigated in modern scientific articles and conference papers [46]-[80]. Main disadvantage of all types of fixed discontinuities is the absence of adjustment option. This results in the deviations of obtained in practice characteristics from the simulated and optimized ones. This effect can be improved or eliminated by the application of metal posts in the waveguide polarizers. Posts provide the possibility of fine tuning of a polarizer after its manufacturing and the option of simultaneous processing of signals with two orthogonal linear/circular polarizations.

Therefore, the development of new waveguide polarizer designs with the possibility of simultaneous simple integration into corrugated horn antennas and tuning of the characteristics after device's fabrication remains a relevant engineering problem. It is solved in the current research. In the following sections a new waveguide polarizer for the dual/single circular polarization radars and satellite information systems is developed based on a circular guide with metal posts. Technical requirements for the development are obtaining of voltage standing wave ratio (VSWR) for the fundamental modes $\mathrm{TE}_{11}$ of both linear polarizations below 1.6 and cross polarization level greater than $30 \mathrm{~dB}$ in the whole operating frequency band 7.4-8.5 GHz. The polarizer satisfying all the requirements is simulated and optimized numerically. Besides, the fabrication of the physical design and experimental verification of the obtained results were performed and presented in the article. 


\section{DESIGN OF A COMPACT CIRCULAR WAVEGUIDE POLARIZER WITH POSTS}

General design of the polarizer and its longitudinal section are shown in Fig. 1. The polarizer consists of a circular waveguide, two flanges and three pairs of posts, which introduce required phase difference between perpendicular linear polarizations and provide acceptable matching.
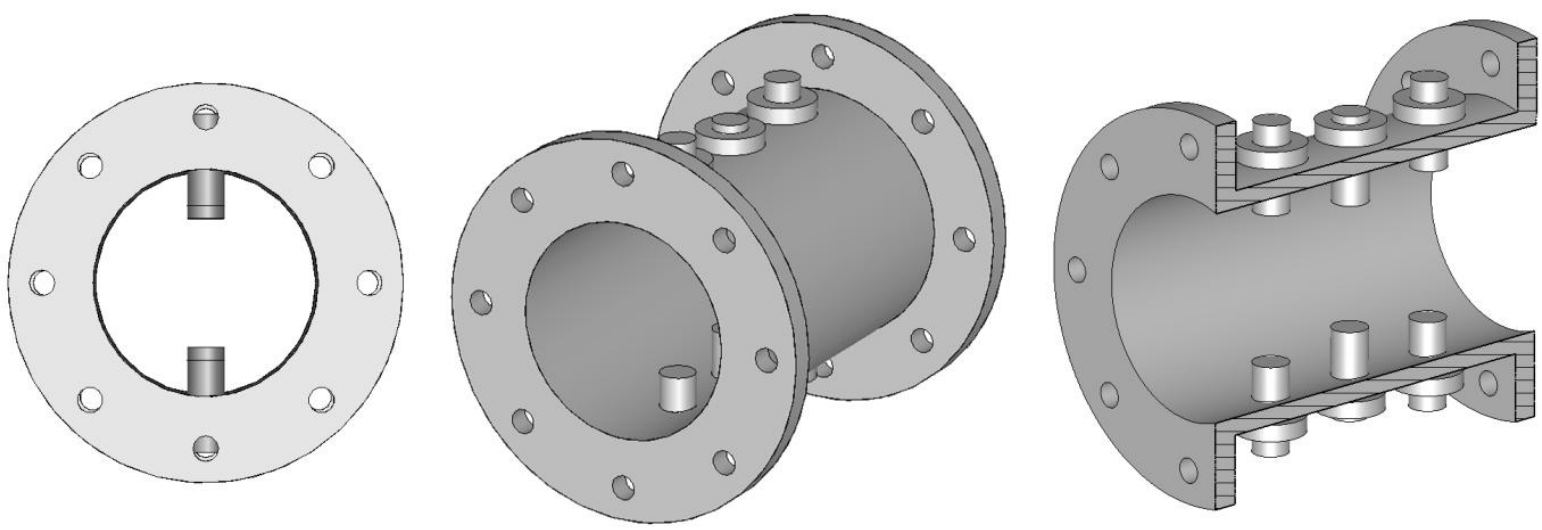

Fig. 1. Design and longitudinal section of the compact polarizer based on a circular waveguide with 3 pairs of posts.

The flanges are needed for the circular waveguide polarizer's connection to a corrugated horn antenna from the one waveguide side and to an orthomode transducer from the other one. Suggested circular waveguide polarizer can be easily integrated in the structure of a corrugated horn antenna and can be manufactured with it as a single device. In this case only one flange for the connection to an orthomode transducer will be required.

For the realization of tuning option in the developed circular waveguide polarizer the posts must be manufactured as adjustable bolts or screws with lock nuts, which are demonstrated in Fig. 1. The increase of the posts height will introduce greater phase difference between perpendicular linear polarizations. On the contrary, the decrease of all posts height will result in the increment of the introduced phase difference.

\section{OPERATION PRINCIPLE OF THE WAVEGUIDE POLARIZER}

In this section we consider the polarization transformation process, which occurs during the propagation of electromagnetic waves in the structure of a suggested circular waveguide polarizer with posts. Fig. 2 demonstrates the situation, when an electromagnetic wave with circular polarization enters the waveguide port of a polarizer. There are two possible types of circular polarization, namely: left hand circular polarization (LHCP) and right hand circular polarization (RHCP). Fundamental orthogonal circular waveguide modes $\mathrm{TE}_{11}$ with both these polarization types are shown in Fig. 2 at the left waveguide ports. Electric field vectors of the fundamental modes TE 11 with LHCP and RHCP rotate counter-clockwise and clockwise, respectively. 


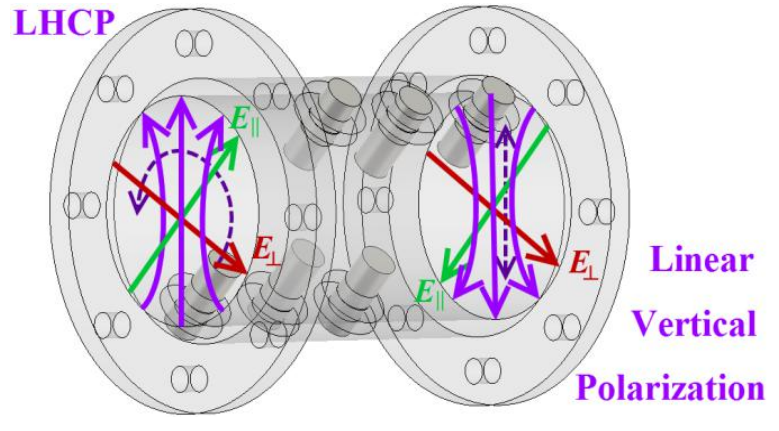

(a)

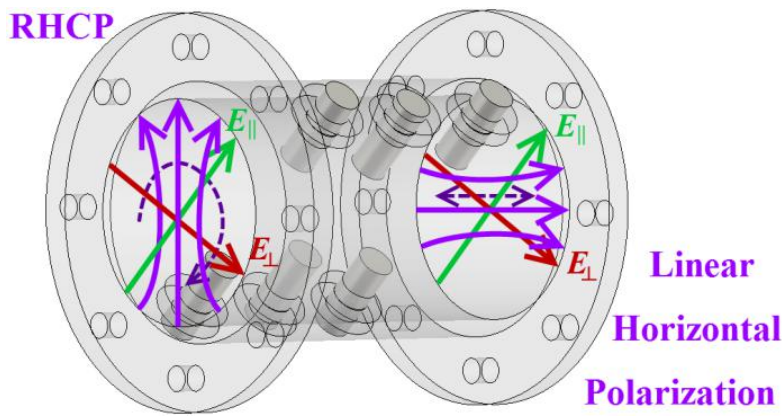

(b)

Fig. 2. Polarizations transformation in a waveguide polarizer: (a) LHCP $\leftrightarrow$ Linear vertical; (b) RHCP $\leftrightarrow$ Linear horizontal.

Let us represent complex amplitude $\dot{\vec{E}}_{\mathrm{CP}}$ of electric field vector of the fundamental mode $\mathrm{TE}_{11}$ with circular polarization as the superposition of two electric field vectors of orthogonal fundamental modes $\mathrm{TE}_{11}$ with linear polarizations:

$$
\dot{\vec{E}}_{\mathrm{CP}}=\dot{\vec{E}}_{\|}+\dot{\vec{E}}_{\perp}=\dot{E}_{\|} \vec{e}_{\|}+\dot{E}_{\perp} \vec{e}_{\perp}=E_{\|} e^{i \varphi_{\|}} \vec{e}_{\|}+E_{\perp} e^{i \varphi_{\perp}} \vec{e}_{\perp},
$$

where $\dot{E}_{\|}=E_{\|} e^{i \varphi_{\|}}$and $\dot{E}_{\perp}=E_{\perp} e^{i \varphi_{\perp}}$ designate complex amplitudes of electric field components with maximum field vectors parallel and perpendicular to the plane of posts axes, respectively; $\vec{e}_{\|}$and $\vec{e}_{\perp}$ are the unit vectors oriented along and orthogonal to the plane of posts axes, respectively. The fact that superposition of these components forms the mode with circular polarization means that the phase difference between them is equal to $90^{\circ}$ and their amplitudes are equal. Let us designate their amplitudes as $A$. In the complex domain $90^{\circ}$ phase difference between the complex amplitudes is equivalent to the factor $e^{ \pm i \cdot 90^{\circ}}= \pm i$. Consequently, we can rewrite formula (1) as follows:

$$
\dot{\vec{E}}_{\mathrm{CP}}=A e^{i \varphi_{\|}} \vec{e}_{\|}+A e^{i\left(\varphi_{\|} \pm 90^{\circ}\right)} \vec{e}_{\perp}=A e^{i \varphi_{\|}}\left(\vec{e}_{\|} \pm i \cdot \vec{e}_{\perp}\right) .
$$

Correctly developed and optimized polarizer introduces additional phase difference, that is close to $90^{\circ}$ in the whole operating frequency band, to the component of electromagnetic mode with electric field vector $\dot{\vec{E}}_{\|}$, which is parallel to the plane of posts axes. Therefore, at the output of a waveguide polarizer the resulting electric field vector is as follows:

$$
\dot{\vec{E}}_{\text {out }}=A e^{i \varphi_{\|}}\left(\vec{e}_{\|} \cdot e^{-i \cdot 90^{\circ}} \pm i \cdot \vec{e}_{\perp}\right)=-i A e^{i \varphi_{\|}}\left(\vec{e}_{\|} \mp \vec{e}_{\perp}\right)=-i A e^{i \varphi_{\|}} \vec{e}_{\text {vert, hor }},
$$

where $\vec{e}_{\text {vert, hor }}$ designates unit vectors, which lie in the transversal plane and are oriented in vertical or horizontal directions, respectively (violet vectors at the right port of a waveguide polarizer in Fig. 2).

Output port of the waveguide polarizer is connected to an orthomode transducer, which carries out the separation of input electromagnetic waves with perpendicular vertical and horizontal polarizations and their direction to two isolated ports. This completes the polarization processing in the receiving antenna system with dual circular polarizations [13]-[15]. 
Journal of Microwaves, Optoelectronics and Electromagnetic Applications, Vol. 20, No. 3, September 2021

DOI: http://dx.doi.org/10.1590/2179-10742021v20i31183

\section{RESULTS OF THE OPTIMIZATION OF WAVEGUIDE POLARIZER CHARACTERISTICS}

This section presents the optimized for operating X-band design of a circular waveguide polarizer with 3 antiphase posts. Numerical simulation and optimization were performed using finite elements method in the frequency domain. It allows to perform calculations more accurately than the finite difference time domain method, because it applies a tetrahedral mesh, which provides better conformance to the cylindrical geometry of a circular waveguide and posts. Besides, finite elements method in the frequency domain provides faster convergence than the finite difference time domain method, which was demonstrated in [81], [82]. The matching, phase and polarization characteristics of a circular waveguide polarizer were simulated and optimized simultaneously. The detailed inner structure of the obtained optimized design of a circular waveguide polarizer and its dimensions, which are indicated in millimeters, are presented in Fig. 3.

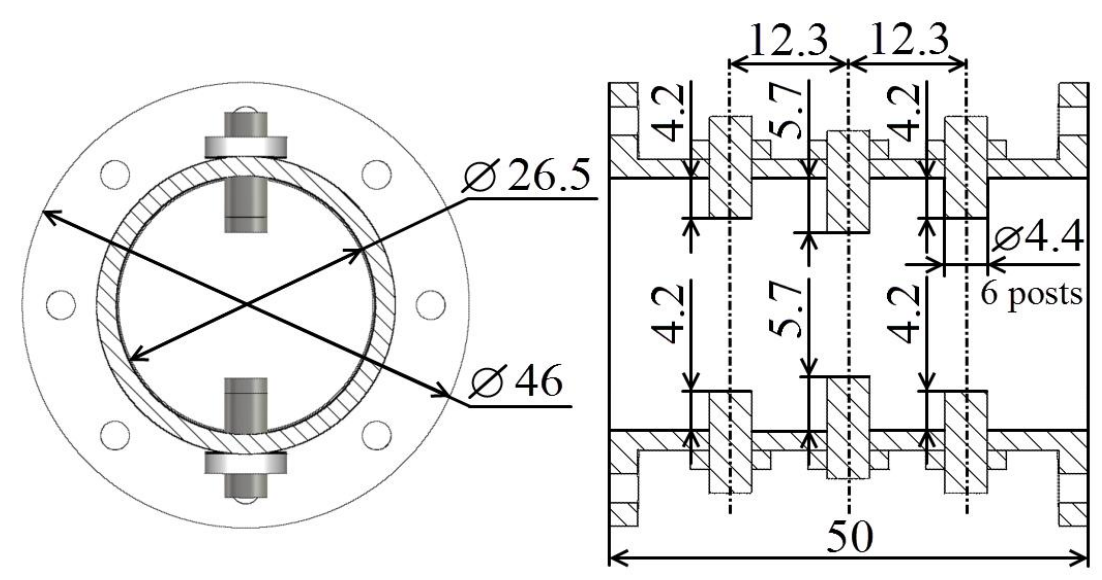

Fig. 3. Inner structure and dimensions (in $\mathrm{mm}$ ) of the optimized X-band circular waveguide polarizer with 3 pairs of posts.

Now let us consider the results of numerical simulations of the obtained optimal design of a circular waveguide polarizer. Fig. 4 presents the VSWR frequency dependences on frequency in the operating $\mathrm{X}$-band for the fundamental modes $\mathrm{TE}_{11}$ of both perpendicular linear polarizations. The dashed green curve corresponds to the fundamental mode $\mathrm{TE}_{11}$ with electric field vector $\vec{E}_{\|}$oriented parallel to the posts axes plane. In Fig. 4 the solid red curve demonstrates VSWR of the fundamental mode $\mathrm{TE}_{11}$ with electric field vector $\vec{E}_{\perp}$ oriented perpendicularly to the posts axes plane.

Having analyzed solid red curve in Fig. 4, we can conclude that the maximal level of VSWR of the fundamental mode $\mathrm{TE}_{11}$ with electric field vector $\vec{E}_{\perp}$ oriented perpendicularly to the posts axes plane is equal to 1.53 . It is reached at the lowest frequency of the operating X-band, that equals $7.4 \mathrm{GHz}$. VSWR for this polarization type decreases with increasing frequency in the sub range from $7.4 \mathrm{GHz}$ to $8.09 \mathrm{GHz}$. This phenomenon can be explained from the physical point of view. At these lower frequencies all 6 posts have heights less than 1/8 part of the wavelength in a circular waveguide. 


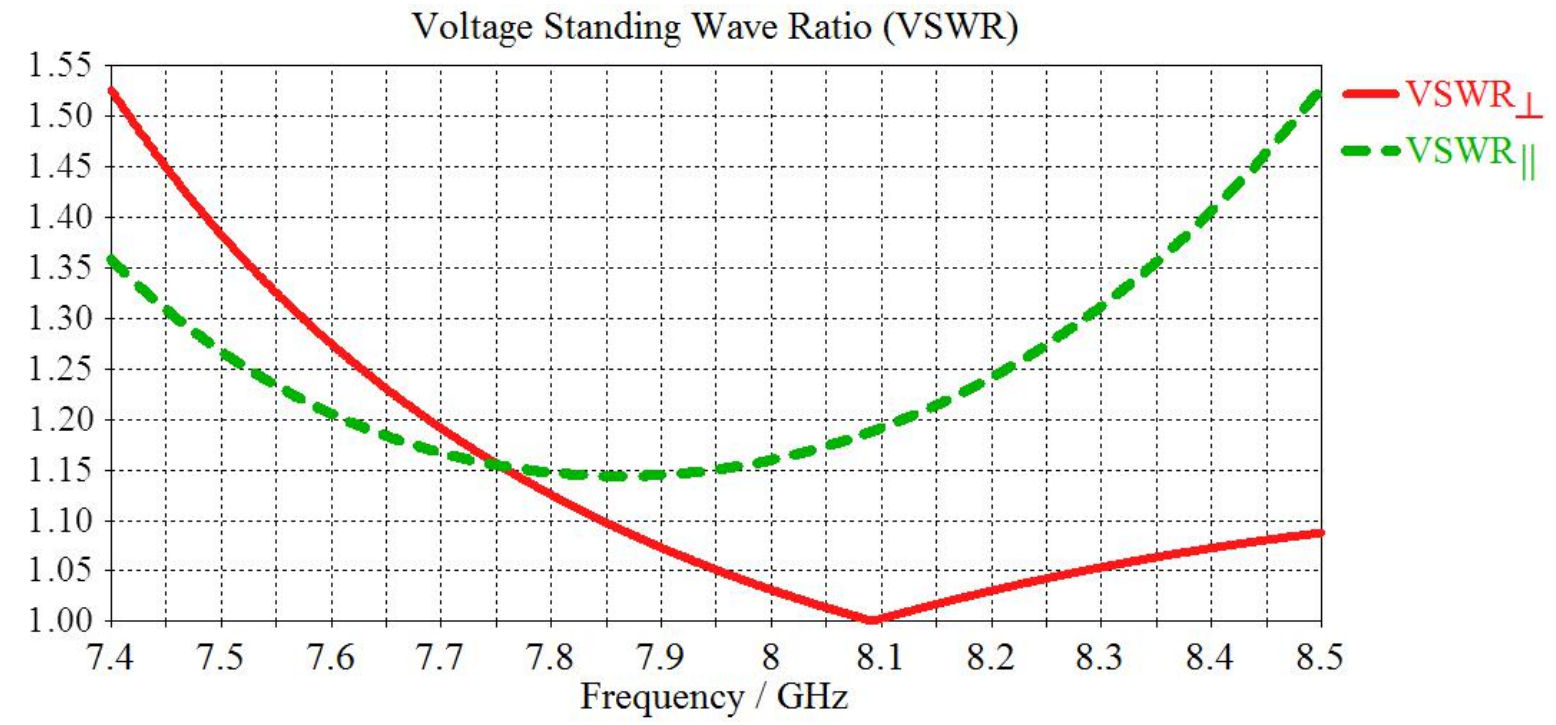

Fig. 4. Dependences of VSWR on frequency for the optimized X-band circular waveguide polarizer with 3 pairs of posts.

Consequently, each pair of oppositely located posts has total height of less than quarter wavelength in the guide. Posts of such height, which are located perpendicularly to the electric field vectors, are equivalent to inductances. Reactance of this type shunts the waveguide at lower frequencies. On the contrary, at higher frequencies of the operating X-band (from $8.09 \mathrm{GHz}$ to $8.5 \mathrm{GHz}$ ) posts, which are located perpendicularly to the electric field vectors, are equivalent to capacitances. In this case the posts shunt the waveguide at higher frequencies. Frequency of $8.09 \mathrm{GHz}$ corresponds to the resonance of equivalent input impedance of the polarizer, which results in perfect matching of the structure.

Analysis of the dashed green curve in Fig. 4 reveals that the maximal level of VSWR of the fundamental mode $\mathrm{TE}_{11}$ with electric field vector $\vec{E}_{\|}$oriented parallel to the posts axes plane is also equal to 1.53. It is reached at the highest frequency of the operating X-band equal to $8.5 \mathrm{GHz}$. Therefore, the quality of the matching of the polarizer's structure is limited by the highest level of VSWR of the fundamental mode $\mathrm{TE}_{11}$ with electric field vector $\vec{E}_{\perp}$ oriented perpendicularly to the posts axes plane at the lowest frequency and by the highest level of VSWR of the fundamental mode TE 11 with electric field vector $\vec{E}_{\|}$oriented parallel to the posts axes plane at the highest frequency.

Fig. 5 demonstrates simulated frequency dependence of the phase difference between perpendicular linear polarizations of an optimized for X-band design of a circular waveguide polarizer with 3 pairs of antiphase cylindrical posts.

In Fig. 5 we observe that the phase difference between perpendicular linear polarizations, which is introduced by the optimized circular waveguide polarizer, has quasi-parabolic frequency dependence that is typical for polarizer structures based on transmission lines loaded by reactive discontinuities [13], [15], [40]-[42]. Phase difference between perpendicular linear polarizations of the optimized polarizer is equal to the required in ideal case value of $90^{\circ}$ only at two frequencies of $7.54 \mathrm{GHz}$ and 8.46 GHz. Within the whole operating X-band 7.4-8.5 GHz phase difference between perpendicular 
Journal of Microwaves, Optoelectronics and Electromagnetic Applications, Vol. 20, No. 3, September 2021

DOI: http://dx.doi.org/10.1590/2179-10742021v20i31183

linear polarizations is in the range of $90^{\circ} \pm 3.5^{\circ}$. Its maximal deviation from $90^{\circ}$ is observed in the minimum of the shown quasi-parabolic dependence at the frequency of $8 \mathrm{GHz}$, which is approximately equal to the central frequency of the operating band.

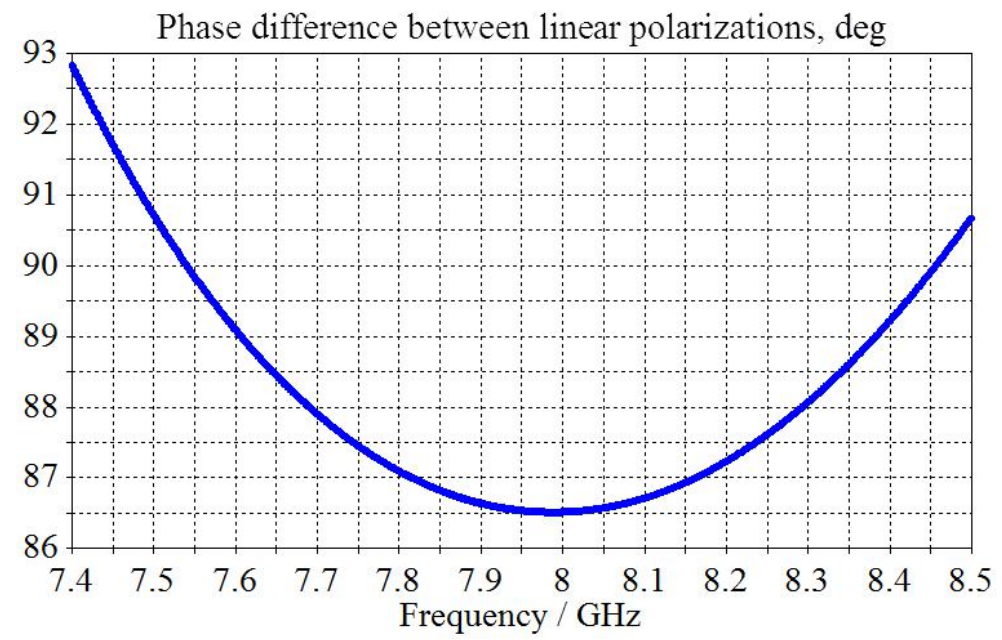

Fig. 5. Phase difference between perpendicular linear polarizations of the optimized circular waveguide polarizer.

Consequently, in the whole operating X-band 7.4-8.5 GHz optimized structure of the developed circular waveguide polarizer with 3 anti-phase posts provides effective phase difference between perpendicular linear polarizations, which allows to perform the required transformation of polarization from circular to linear type or vice versa.

The simulated dependence of polarization ellipticity of the optimized circular waveguide polarizer on the frequency in the operating X-band is presented in Fig. 6.

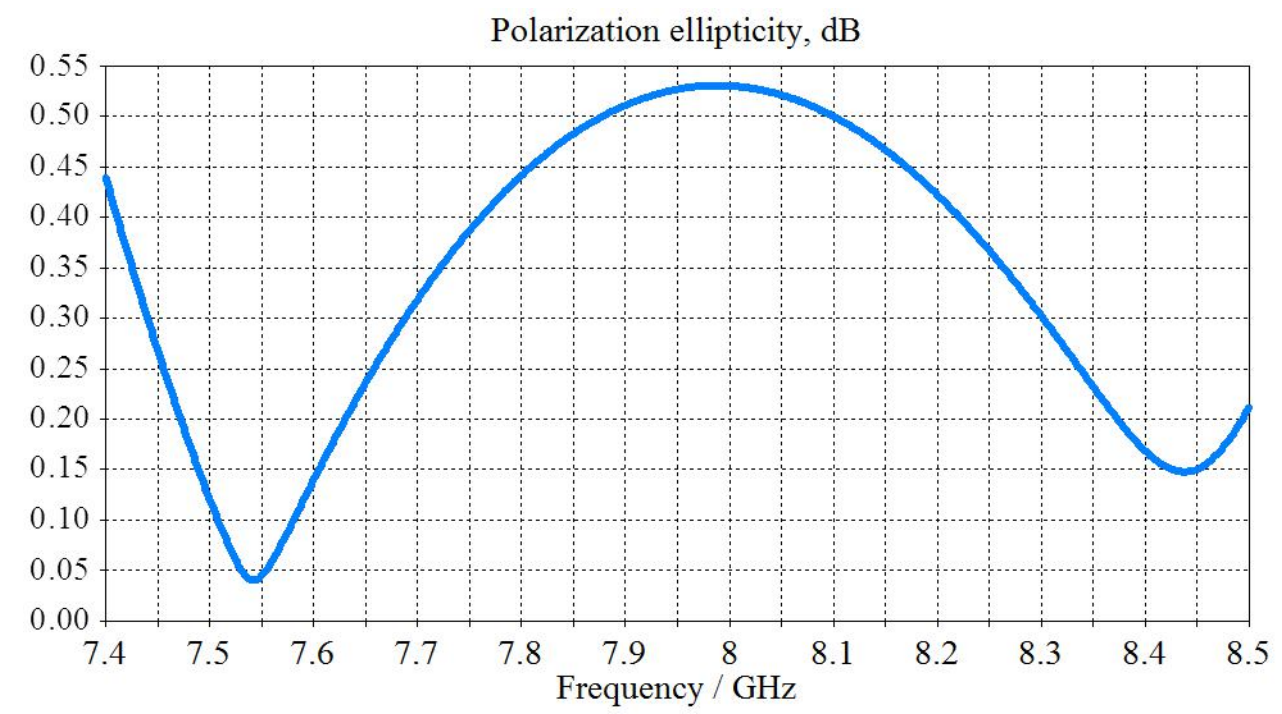

Fig. 6. Polarization ellipticity versus frequency for the optimized design of the circular waveguide polarizer.

In Fig. 6 it is seen that the frequency dependence of polarization ellipticity has two local minima at the frequencies of $7.54 \mathrm{GHz}$ and $8.44 \mathrm{GHz}$. The frequencies corresponding to these minima are almost equal to the frequencies, at which the phase difference between perpendicular linear polarizations is equal to $90^{\circ}$. Small deviation of the second frequency corresponding to minimum is 
Journal of Microwaves, Optoelectronics and Electromagnetic Applications, Vol. 20, No. 3, September 2021 DOI: http://dx.doi.org/10.1590/2179-10742021v20i31183

caused by the imperfect matching of the waveguide polarizer, which leads to inequality of the amplitudes of electric field components $E_{\|}$and $E_{\perp}$. In the whole operating X-band maximal level of the polarization ellipticity of an optimized circular waveguide polarizer design is $0.53 \mathrm{~dB}$. It is observed at the frequency of $8 \mathrm{GHz}$, which exactly coincides with the frequency of maximal deviation of phase difference between perpendicular linear polarizations from $90^{\circ}$. The difference in these frequencies is absent due to good matching of the structure in the central part of the operating band, where VSWR is below 1.2 (see Fig. 4).

Fig. 7 presents the dependence of simulated numerically cross polarization level on frequency for the optimized design of a circular waveguide polarizer with 3 pairs of anti-phase posts in the operating X-band 7.4-8.5 GHz.

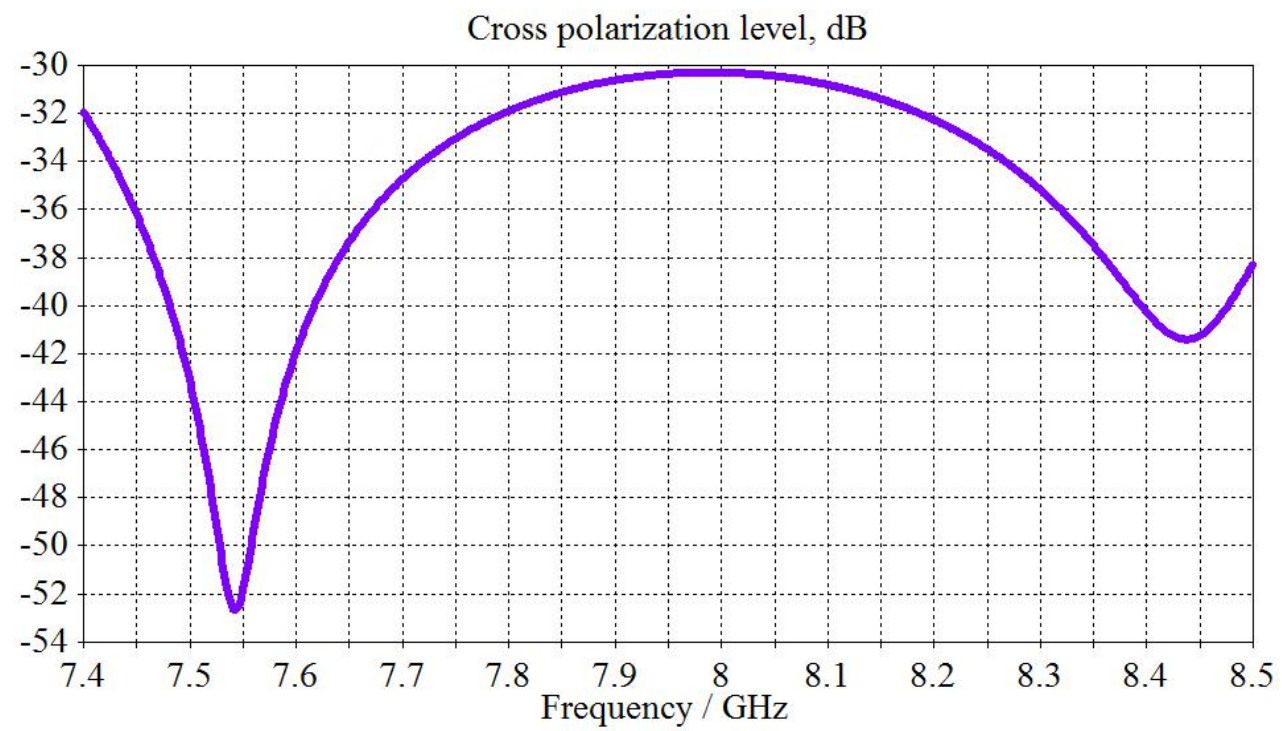

Fig. 7. Dependence of cross polarization level on frequency for the optimized circular waveguide polarizer.

In Fig. 7 it is seen that the optimized design of a circular waveguide polarizer with antiphase posts provides cross polarization level greater than $30 \mathrm{db}$ in the whole operating band. The extreme levels of cross polarization level are observed at the frequencies of $7.54 \mathrm{GHz}$ (cross polarization level greater than $52 \mathrm{~dB}$ ) and $8.44 \mathrm{GHz}$ (cross polarization level greater than $41 \mathrm{~dB}$ ). On the whole, developed circular waveguide polarizer provides excellent polarization performance and high isolation between the signals with orthogonal circular polarizations, which is an important requirement in modern radar, telecommunication and other radio engineering systems.

\section{PHYSICAL DESIGN AND MEASURED CHARACTERISTICS OF THE WAVEGUIDE POLARIZER}

In order to verify the electromagnetic performance of a suggested circular waveguide polarizer an experimental prototype was fabricated and measured. Fig. 8 demonstrates the polarizer with 3 pairs of tunable anti-phase posts in the structure of complete antenna feed for dual-polarization satellite communication systems. The designed antenna system is applied for the simultaneous reception of information signals at two orthogonal circular polarizations. 

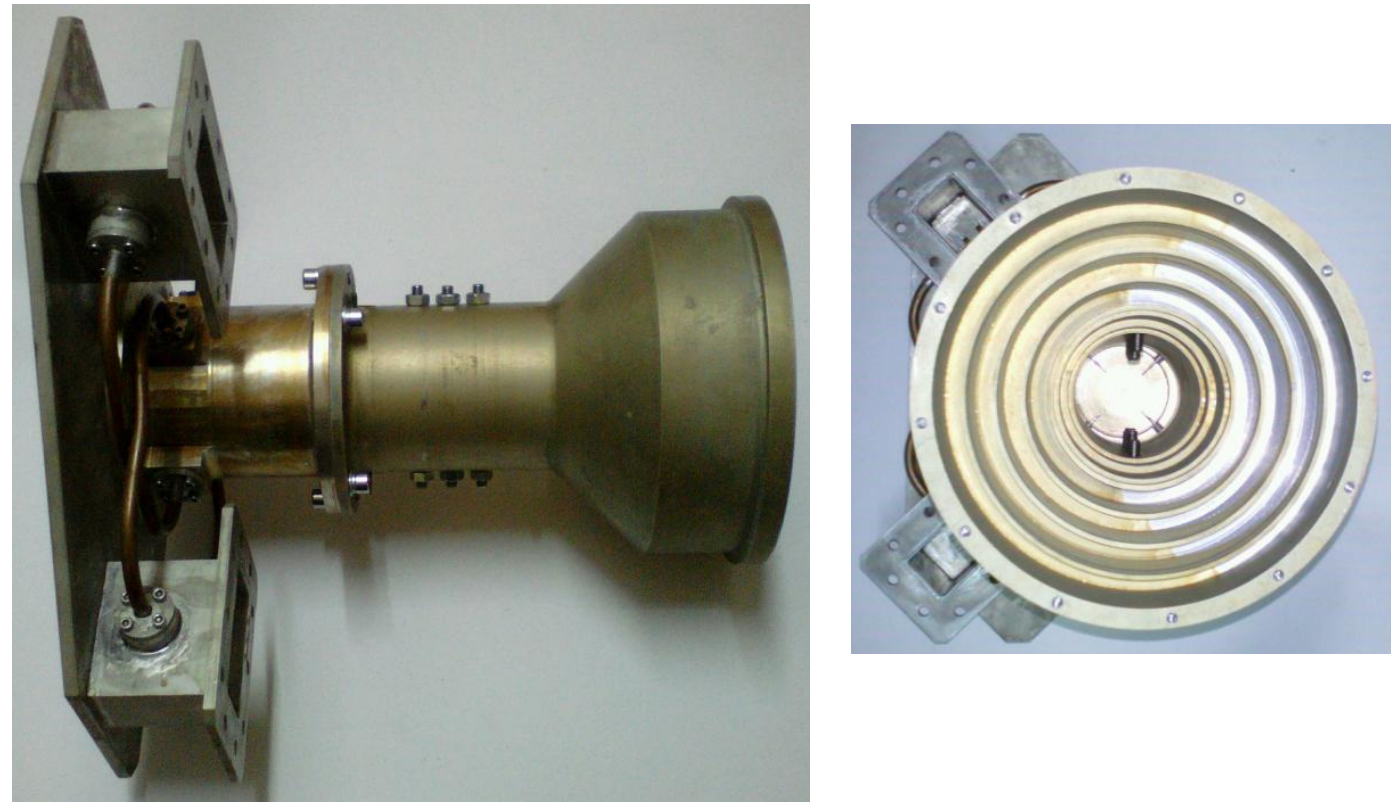

Fig. 8. Design of a circular waveguide polarizer integrated into dual-circular polarization antenna feed system.

First, the antenna, which is presented in Fig. 8, was tested in the transmission mode in order to measure its matching performance. Rectangular waveguides were connected to a scalar network analyzer, that allowed to measure VSWR for the fundamental modes with both polarizations with electric field vectors $\vec{E}_{\|}$and $\vec{E}_{\perp}$ oriented parallel and perpendicularly to the posts axes plane. In this case the orthomode transducer was connected in such a way that its probes were located in the plane of polarizer's posts and in the orthogonal plane. The results of the VSWR measurements are presented in Fig. 9. The solid red curve shows the frequency dependence of VSWR of the fundamental mode $\mathrm{TE}_{11}$ with electric field vector $\vec{E}_{\perp}$ oriented perpendicularly to the posts axes plane. The dashed green curve corresponds to the mode $\mathrm{TE}_{11}$ with electric field $\vec{E}_{\|}$oriented parallel to the posts axes plane.

As one can observe in Fig. 9, the general behavior of the VSWR for the mode with electric field vector $\vec{E}_{\perp}$ matches well with the theoretical curve, which was shown hereinbefore in Fig. 4. For this polarization perfect matching of the antenna feed system occurs at the frequency of $8.2 \mathrm{GHz}$. For the orthogonal polarization with electric field $\vec{E}_{\|}$the matching improves compared to the theoretical results. The peak level of VSWR is less than 1.23, which is better than the simulated peak level of 1.53. Differences between the results occur due to the inaccuracies of the fabrication and to the influence on the matching of reflections in a corrugated horn and in an orthomode transducer. Consequently, in the whole operating frequency band 7.4-8.5 GHz developed antenna feed system with integrated circular waveguide polarizer provides good matching with VSWR less than 1.7. 


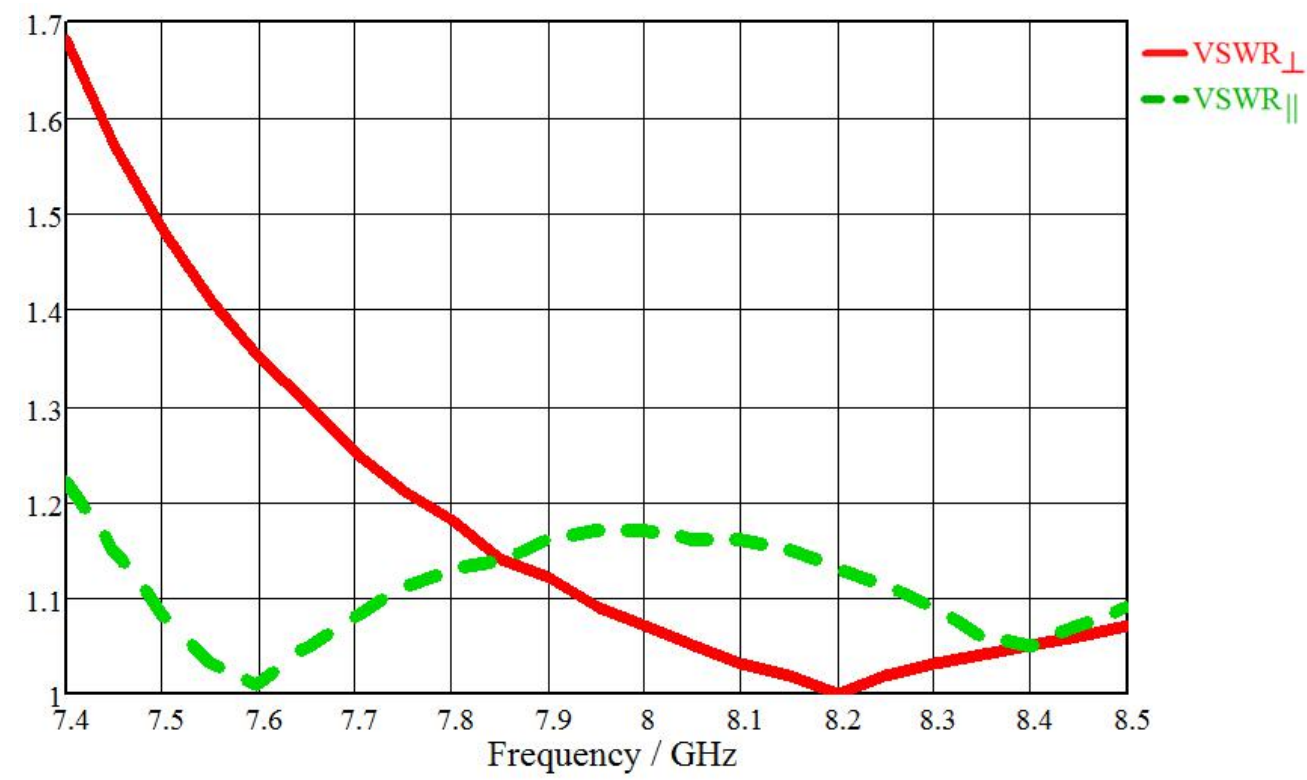

Fig. 9. Measured VSWR of the fabricated antenna feed system with integrated circular waveguide polarizer.

The simplest way to test the polarization performance of the polarizer and of the complete dualcircular polarization antenna feed system is to measure its polarization ellipticity. Experimental measurement of the polarization ellipticity is performed using the designed antenna feed system in the transmission mode with the polarizer posts' plane oriented at the angle $45^{\circ}$ respectively to the orthomode transducer's probes. The reception of the radiated electromagnetic waves was made by the pyramidal horn antenna, which mostly receives only the signal transmitted by the electromagnetic waves with electric field vectors oriented perpendicularly to the waveguide and horn broad walls. In order to measure the polarization ellipticity (as the ratio between great and small half-axes of the polarization ellipse), the receiving pyramidal horn must have the possibility of rotation in the plane perpendicular to the wave's propagation direction. Measured by the described procedure axial ratio was expressed in $\mathrm{dB}$ and presented in Fig. 10.

Comparison of Fig. 6 and Fig. 10 reveals that the behavior of polarization ellipticities, which were modeled theoretically and measured experimentally, is similar. Peak levels of the polarization ellipticity match well. In the most part of the operating frequency band 7.4-8.5 GHz measured ellipticity is less than $0.54 \mathrm{~dB}$. The worst measured polarization ellipticity is observed at the lowest frequency of $7.4 \mathrm{GHz}$. It is equal to $0.68 \mathrm{~dB}$. The deterioration of the poalrization ellipticity and its frequency shift within the operating band are caused by the inaccuracies of the manufacturing and by the influence of cross polarization discrimination of the corrugated horn and orthomode transducer. 
Polarization ellipticity, $\mathrm{dB}$

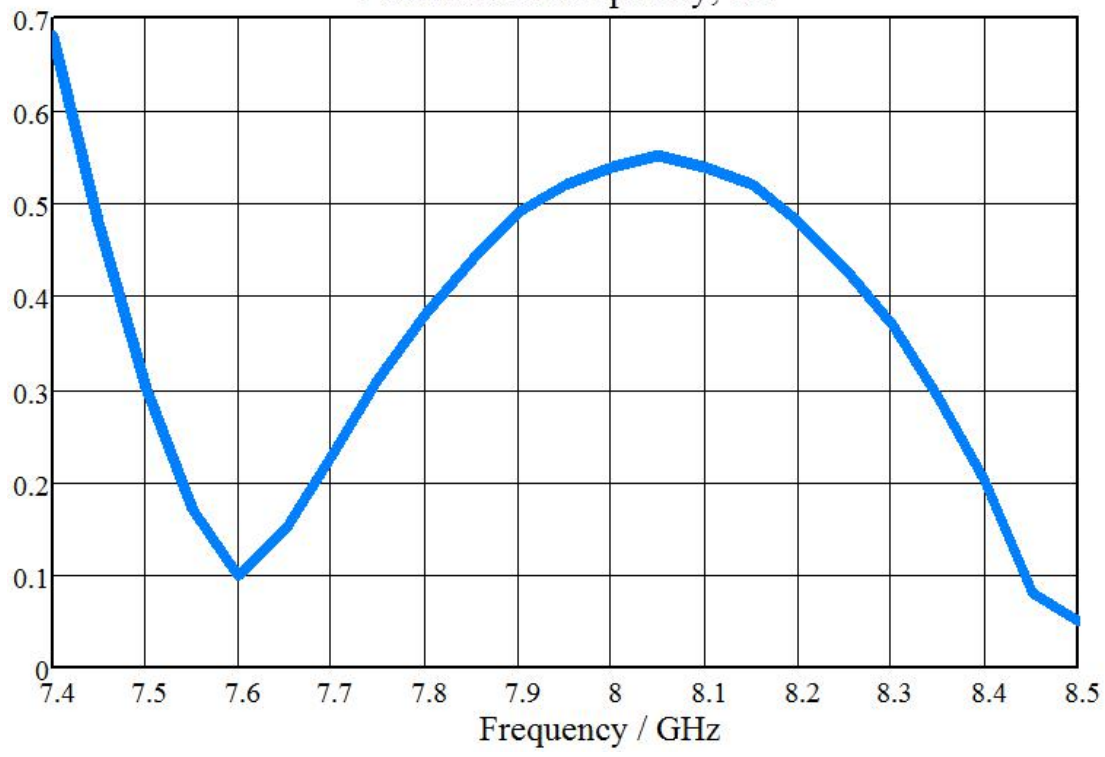

Fig. 10. Polarization ellipticity of the fabricated antenna feed system with integrated circular waveguide polarizer.

\section{CONCLUSIONS}

A new circular waveguide polarizer with posts was developed, investigated and optimized for the operating X-band 7.4-8.5 GHz. The design of a polarizer is based on a circular waveguide. In order to provide required phase difference between perpendicular linear polarizations close to $90^{\circ}$ three pairs of antiphase posts were applied in the structure of a suggested circular waveguide polarizer.

Developed circular waveguide polarizer has flanges diameter equal to $46 \mathrm{~mm}$. The total length of the optimized structure is $50 \mathrm{~mm}$. The application of cylindrical posts in the design allows to perform fine tuning of electromagnetic characteristics of a waveguide polarizer after its manufacturing.

Within the frequency band 7.4-8.5 GHz an optimized circular waveguide polarizer with posts provides simulated VSWR below 1.55. Simulated phase difference between fundamental modes with perpendicular linear polarizations of the developed polarizer is in the range $90^{\circ} \pm 3.5^{\circ}$. Calculated polarization ellipticity of the optimized circular waveguide polarizer design is below $0.55 \mathrm{~dB}$. Modeled cross polarization level of the developed waveguide polarizer is greater than $30 \mathrm{~dB}$.

Experimental measurements of a dual-circular polarization antenna feed system with integrated polarizer showed that its VSWR is less than 1.7 and the polarization ellipticity is less than $0.7 \mathrm{~dB}$. Measured experimentally and simulated theoretically results are in good agreement.

Therefore, suggested circular waveguide polarizer with posts simultaneously provides efficient matching and polarization characteristics. Developed new circular waveguide polarizer can be effectively applied in modern weather radars and satellite information systems.

\section{REFERENCES}

[1] W. L. Stutzman, Polarization in Electromagnetic Systems. Norwood, MA, USA: Artech House, 2018.

[2] S. Piltyay, A. Bulashenko, H. Kushnir, and O. Bulashenko, "Information resources economy in satellite systems based on new microwave polarizers with tunable posts," Path of Science, vol. 6, no. 11, pp. 5001-5010, 2020. DOI: $10.22178 /$ pos.55-1. 
[3] J. T. Srisumantyo, et al., "Airborne circularly polarized synthetic aperture radar," IEEE Journal of Selected Topics in Applied Earth Observations and Remote Sensing, pp. 1-17, 2020. DOI: 10.1109/JSTARS.2020.3045032.

[4] P. R. Drake, J. Bourgeois, A. P. Hopf, F. Lok, and D. McLaughlin, "Dual-polarization X-band phased array weather radar: Technology update," 2014 International Radar Conference, Lille, France, October 2014. DOI: 10.1109/RADAR.2014.7060423.

[5] R. Baqué, et al., "Ultra-high resolution and long range X-band airborne SAR system," 2018 International Conference on Radar (RADAR), Brisbane, Australia, August 2018. DOI: 10.1109/RADAR.2018.8557220.

[6] H. Niu, C. Ma, P. Han, S. Li, Q. Ma, and S. Zhang, "Research on safety modeling and analysis to the task process of airborne weather system," IEEE 20th International Conference on Software Quality, Reliability and Security Companion (QRS-C), Macau, China, December 2020. DOI: 10.1109/QRS-C51114.2020.00062.

[7] M. Vizcarro, S. Turso, C. G. Salzburg, and T. Bertuch, "A dual-polarized X-band patch antenna sub-array with low cross-polarization for weather radar applications," 20th International Radar Symposium (IRS), Ulm, Germany, June 2019. DOI: $10.23919 /$ IRS.2019.8768175.

[8] F. Dubrovka, S. Martunyuk, R. Dubrovka, M. Lytvyn, S. Lytvyn, Yu. Ovsianyk, et al., "Circularly polarised X-band H11- and H21-modes antenna feed for monopulse autotracking ground station", IEEE Ukrainian Microwave Week (UkrMW), Kharkiv, Ukraine, September 2020, pp. 196-202. DOI: 10.1109/UkrMW49653.2020.9252600.

[9] F. F. Dubrovka, and S. I. Piltyay, "A high performance ultrawideband orthomode transducer and a dual-polarized quadridged horn antenna based on it", Proceedings of VIII Int. Conf. on Antenna Theory and Techniques (ICATT), Kyiv, Ukraine, September 2011, pp. 176-178. DOI: 10.1109/ICATT.2011.6170737.

[10] M. Kamikura, M. Naruse, S. Asayama, N. Satou, W. Shan, and Y. Sekimoto, "Development of a submillimeter doubleridged waveguide ortho-mode transducer (OMT) for the $385-500 \mathrm{GHz}$ band", Journal of Infrared Millimeter and Terahertz Waves, vol. 31, no. 6, pp. 697-707, March 2010. DOI: 10.1007/s10762-010-9632-1.

[11] T.-L. Zhang, Z.-H. Yan, L. Chen, and F.-F. Fan, "Design of broadband orthomode transducer based on double ridged waveguide", Proceeding of International Conference on Microwave and Millimeter Wave Tech. (ICMMT 2010), Chengdu, China, May 2010, pp. 765-768. DOI: 10.1109/ICMMT.2010.5525061.

[12] E. Menargues, S. Capdevila, T. Debogovic, et al., "Four-port broadband orthomode transducer enabling arbitrary interelement spacing", IEEE Transactions on Microwave Theory and Techniques, vol. 66, no. 12, pp. 5521-5530, November 2018. DOI: 10.1109/TMTT.2018.2878208.

[13] G. Virone, R. Tascone, O. A. Peverini, G. Addamo, and R. Orta, "Combined-phase-shift waveguide polarizer", IEEE Microwave and Wireless Components Letters, vol. 18, no. 8, pp. 509-511, August 2008. DOI: 10.1109/LMWC.2008.2001005.

[14] O. A. Peverini, G. Virone, G. Addamo, and R. Tascone, "Development of passive microwave antenna-feed systems for wide-band dual-polarisation receivers", IET Microwaves, Antennas and Propagation, vol. 5, no. 8, pp. 1008-1015, June 2011. DOI: 10.1049/iet-map.2010.0340.

[15] S. I. Piltyay, "High performance extended C-band 3.4-4.8 GHz dual circular polarization feed system", XI International Conference on Antenna Theory and Techniques (ICATT), Kyiv, Ukraine, May 2017, pp. 284-287. DOI: 10.1109/ICATT.2017.7972644.

[16] J. A. Ruiz-Cruz, M. M. Fahmi, S. A. Fouladi, and R. R. Mansour, "Waveguide antenna feeders with integrated reconfigurable dual circular polarization", IEEE Transactions on Microwave Theory and Techniques, vol. 59, no. 12, pp. 3365-3374, December 2011. DOI: 10.1109/TMTT.2011.2170581.

[17] F. F. Dubrovka, S. I. Piltyay, R. R. Dubrovka, M. M. Lytvyn, and S. M. Lytvyn, "Optimum septum polarizer design for various fractional bandwidths," Radioelectronics and Communications Systems, vol. 63, no. 1, pp. 15-23, January 2020. DOI: $10.3103 / \mathrm{S} 0735272720010021$.

[18] F. Dubrovka, S. Piltyay, O. Sushko, R. Dubrovka, M. Lytvyn, and S. Lytvyn, "Compact X-band stepped-thickness septum polarizer", IEEE Ukrainian Microwave Week (UkrMW), Kharkiv, Ukraine, September 2020, pp. 135-138. DOI: 10.1109/UkrMW49653.2020.9252583.

[19] J. A. Ruiz-Cruz, J. R. Montejo-Garai, C. A. Leal-Sevillano, and J. M. Rebollar, "Orthomode transducers with folded double-symmetry junctions for broadband and compact antenna feeds", IEEE Transactions on Antennas and Propagation, vol. 66, no. 3, pp. 1160-1168, March 2018. DOI: 10.1109/TAP.2018.2794364.

[20] G. Virone, O. A. Peverini, M. Lumia, M. Z. Farooqui, et al., "W-Band orthomode transducer for dense focal-plane clusters", IEEE Microwave and Wireless Components Letters, vol. 25, no. 2, pp. 85-87, February 2015. DOI: 10.1109/LMWC.2014.2373638.

[21] F. F. Dubrovka, and S. I. Piltyay, "Novel high performance coherent dual-wideband orthomode transducer for coaxial horn feeds", XI International Conference on Antenna Theory and Techniques (ICATT), Kyiv, Ukraine, May 2017, pp. 277-280. DOI: 10.1109/ICATT.2017.7972642.

[22] S. I. Piltyay, "Enhanced C-band coaxial orthomode transducer", Visnyk NTUU KPI Seriia - Radiotekhnika, Radioaparatobuduvannia, vol. 58, pp. 27-34, September 2014. DOI: 10.20535/RADAP.2014.58.27-34.

[23] C. A. Leal-Sevillano, T. J. Reck, G. Chattopadhyay, J. A. Ruiz-Cruz, J. R. Montejo-Garai, and J. M. Rebollar, "Development of a wideband compact orthomode transducer for the 180-270 GHz band", IEEE Transactions on Terahertz Science and Technology, vol. 4, no. 5, pp. 634-636, September 2014. DOI: 10.1109/TTHZ.2014.2336540.

[24] F. F. Dubrovka and S. I. Piltyay, "Electrodynamics boundary problem solution for sectoral coaxial ridged waveguides by integral equation technique", Radioelectronics and Communications Systems, vol. 55, no. 5, pp. 191-203. May 2012. DOI: $10.3103 /$ S0735272712050019.

[25] F. F. Dubrovka and S. I. Piltyay, "Eigenmodes of sectoral coaxial ridged waveguides", Radioelectronics and Communications Systems, vol. 55, no. 6, pp. 239-247. June 2012. DOI: 10.3103/S0735272712060015. 
[26] S. I. Piltyay, "Numerically effective basis functions in integral equation technique for sectoral coaxial ridged waveguides", 14-th International Conference on Mathematical Methods in Electromagnetic Theory (MMET), Kyiv, Ukraine, August 2012, pp. 492-495. DOI: 10.1109/MMET.2012.6331195.

[27] F. F. Dubrovka and S. I. Piltyay, "Prediction of eigenmodes cutoff frequencies of sectoral coaxial ridged waveguides", XI International Conference on Modern Problems of Radio Engineering, Telecommunications and Computer Science. Slavske, Ukraine, February 2012, pp. 191.

[28] F. F. Dubrovka and S. I. Piltyay, "Eigenmodes analysis of sectoral coaxial ridged waveguides by transverse fieldmatching technique. Part 1. Theory”, Visnyk NTUU KPI Seriia - Radiotekhnika, Radioaparatobuduvannia, vol. 54, pp. 13-23. 2013. DOI: 10.20535/RADAP.2013.54.13-23.

[29] F. F. Dubrovka and S. I. Piltyay, "Eigenmodes analysis of sectoral coaxial ridged waveguides by transverse fieldmatching technique. Part 2. Results", Visnyk NTUU KPI Seriia - Radiotekhnika, Radioaparatobuduvannia, vol. 55, pp. 13-23. 2013. DOI: 10.20535/RADAP.2013.55.13-23.

[30] F. F. Dubrovka and S. I. Piltyay, "Eigenmodes of coaxial quad-ridged waveguides. Theory", Radioelectronics and Communications Systems, vol. 57, no. 1, pp. 1-30. January 2014. DOI: 10.3103/S0735272714010014.

[31] F. F. Dubrovka and S. I. Piltyay, "Eigenmodes of coaxial quad-ridged waveguides. Numerical results", Radioelectronics and Communications Systems, vol. 57, no. 2, pp. 59-69. February 2014. DOI: 10.3103/S0735272714020010.

[32] F. F. Dubrovka and S. I. Piltyay, "Boundary problem solution for eigenmodes in coaxial quad-ridged waveguides", Information and Telecommunication Sciences, vol. 5, no. 1, pp. 48-61. 2014.DOI: 10.20535/2411-2976.12014.48-61.

[33] P. J. B. Clarricoats, A. D. Olver, Corrugated Horns for Microwave Antennas. London, UK: Peter Peregrinus Ltd., 1984.

[34] V. Naydenko, et al., "Evolution of radiopulses radiated by Hertz's dipole in vacuum", 12-th International Conference on Mathematical Methods in Electromagnetic Theory (MMET), Odesa, Ukraine, July 2008, pp. 294-297. DOI: 10.1109/MMET.2008.4580972.

[35] A. D. Olver., P. J. B. Clarricoats, A. A. Kishk, L. Shafai, Microwave Horns and Feeds. London: The Institution of Electrical Engineers, 1994.

[36] W. L. Stutzman, G. A. Thiele, Antenna Theory and Design. Hoboken, New Jersey, USA: John Wiley \& Sons, 2013.

[37] F. F. Dubrovka, et al., "Ultrawideband microwave biconical high-gain antenna for dual-band systems of omnidirectional radio monitoring", Radioelectronics and Communications Systems, vol. 63, no. 12, pp. 619-632. December 2020. DOI: 10.3103/S0735272720120018.

[38] T. A. Milligan, Modern Antenna Design. Hoboken, New Jersey, USA: John Wiley \& Sons, 2005.

[39] F. F. Dubrovka, et al., "Eight-channel directional coupler of orthogonal h21 modes in circular waveguide for X-band quasi-monopulse antenna systems", Radioelectronics and Communications Systems, vol. 63, no. 12, pp. 656-665. December 2020. DOI: 10.3103/S0735272720120043.

[40] S. Li, Z. Liu, W. Cao, X. Yu, Y. Wang, and C. Yu, "Design of a Ku-band corrugated horn with good-symmetrical pattern", 12th International Symposium on Antennas, Propagation and EM Theory (ISAPE), Hangzhou, China, December 2018. DOI: 10.1109/ISAPE.2018.8634016.

[41] S. I. Piltyay, A. V. Bulashenko, and I. V. Demchenko, "Wireless sensor network connectivity in heterogeneous 5G mobile systems", IEEE International Conference on Problems of Infocommunications. Science and Technology (PIC S\&T), Kharkiv, Ukraine, October 2020, pp. 508-513.

[42] O. Sushko, et al., "Symmetrically fed 1-10 GHz log-periodic dipole antenna array feed for reflector antennas", IEEE Ukrainian Microwave Week (UkrMW), Kharkiv, Ukraine, September 2020, pp. 222-225. DOI: 10.1109/UkrMW49653.2020.9252778.

[43] M. Bray, "Dual X/Ka-band corrugated feed horn for deep space telecommunications", IEEE International Symposium on Antennas and Propagation (APSURSI), Fajardo, Puerto Rico, June 2016. DOI: 10.1109/APS.2016.7696481.

[44] A. V. Bulashenko, et al., "Energy efficiency of the D2D direct connection system in 5G networks", IEEE International Conference on Problems of Infocommunications. Science and Technology (PIC S\&T), Kharkiv, Ukraine, October 2020, pp. 324-329.

[45] B. Du, E. Kai-Ning Yung, K.-Z. Yang, and W.-J. Zhang, "Wide-band linearly or circularly polarized monopulse tracking corrugated horn", IEEE Transactions on Antennas and Propagation, vol. 50, no. 2, pp. 192-197. February 2002. DOI: 10.1109/8.997994.

[46] S. I. Piltyay, O. Yu. Sushko, A. V. Bulashenko, and I. V. Demchenko, "Compact Ku-band iris polarizers for satellite telecommunication systems”, Telecommunications and Radio Engineering, vol. 79, no. 19, pp. 1673-1690. December 2020. DOI: 10.1615/TelecomRadEng.v79.i19.10.

[47] S. I. Piltyay, A. V. Bulashenko, and I. V. Demchenko, "Waveguide iris polarizers for Ku-band satellite antenna feeds", Journal of Nano- and Electronic Physics, vol. 12, no. 5, pp. 05024-1-05024-5, October 2020. DOI: 10.21272/jnep.12(5).05024

[48] S. I. Piltyay, A. V. Bulashenko, and I. V. Demchenko, "Analytical synthesis of waveguide iris polarizers", Telecommunications and Radio Engineering, vol. 79, no. 18, pp. 1579-1597, November 2020. DOI: 10.1615/TelecomRadEng.v79.i18.10.

[49] A. V. Bulashenko, S. I. Piltyay, and I. V. Demchenko, "Wave matrix technique for waveguide iris polarizers simulation. Theory", Journal of Nano- and Electronic Physics, vol. 12, no. 6, pp. 06026-1-06026-5, December 2020. DOI: 10.21272/jnep.12(6).06026.

[50] A. V. Bulashenko, S. I. Piltyay, and I. V. Demchenko, "Wave matrix technique for waveguide iris polarizers simulation. Numerical results", Journal of Nano- and Electronic Physics, vol. 13, no. 3, pp. 03023-1-03023-5, June 2021. DOI: 10.21272/jnep.13(3).03023.

[51] F. F. Dubrovka and S. I. Piltyay, "A novel wideband coaxial polarizer", IX International Conference on Antenna Theory and Techniques (ICATT), Odesa, Ukraine, September 2013, pp. 473-474. DOI: 10.1109/ICATT.2013.6650816. 
[52] A. V. Bulashenko and S. I. Piltyay, "Equivalent microwave circuit technique for waveguide iris polarizers development", Visnyk NTUU KPI Seriia - Radiotekhnika, Radioaparatobuduvannia, vol. 83, pp. 17-28, December 2020. DOI: $10.20535 /$ RADAP.2020.83.17-28.

[53] A. Bulashenko, S. Piltyay, A. Polishchuk, O. Bulashenko, "New traffic model of M2M Technology in 5G wireless sensor networks", IEEE 2nd International Conference on Advanced Trends in Information Theory (ATIT), Kyiv, Ukraine, November 2020, pp. 125-131. DOI: 10.1109/ATIT50783.2020.9349305.

[54] S. I. Piltyay, A. V. Bulashenko, and I. V. Demchenko, "Compact polarizers for satellite information systems", IEEE International Conference on Problems of Infocommunications. Science and Technology (PIC S\&T), Kharkiv, Ukraine, October 2020, pp. 350-355.

[55] A. V. Bulashenko, S. I. Piltyay, and I. V. Demchenko, "Analytical technique for iris polarizers development”, IEEE International Conference on Problems of Infocommunications. Science and Technology (PIC S\&T), Kharkiv, Ukraine, October 2020, pp. 464-469.

[56] A. V. Bulashenko, S. I. Piltyay, and I. V. Demchenko, "Optimization of a polarizer based on a square waveguide with irises", Science-Based Technologies, vol. 47, no. 3, pp. 287-297, November 2020. (in Ukrainian). DOI: 10.18372/2310-5461.47.14878.

[57] A. V. Bulashenko, S. I. Piltyay, Y. I. Kalinichenko and O. V. Bulashenko, "Tunable square waveguide polarizer with irises and posts", Technical Engineering, vol. 86, no. 2, pp. 108-116, December 2020. (in Ukrainian). DOI: 10.26642/ten-2020-2(86)-108-116.

[58] C. W. Robertson, A. R. Young, K. Ronald, A. W. Cross, and C. G. Whyte, "Circular polariser for use in a gyrotravelling wave amplifier", IET Microwaves, Antennas and Propagation, vol. 7, no. 11, pp. 942-948, 2013. DOI: 10.1049/iet-map.2012.0415.

[59] M.-H. Chung, D.-H. Je, S.-T. Han, and S. R. Kim, "Development of a 85 115 GHz 90-deg phase shifter using corrugated square waveguide", European Microwave Conference (EuMC), Rome, Italy, October 2014, pp. 1146-1149. DOI: 10.1109/EuMC.2014.6986643.

[60] Yu. Tikhov, "Comparison of two kinds of Ka-band circular polarisers for use in a gyro-travelling wave amplifier", IET Microwaves, Antennas and Propagation, vol. 10, no. 2, pp. 147-151, 2016. DOI: 10.1049/iet-map.2015.0292.

[61] F. F. Dubrovka, A. V. Bulashenko, A. M. Kuprii, and S. I. Piltyay, "Analytical and numerical method of constructive synthesis of optimal polarizers based on three irises in square waveguide", Radioelectronics and Communications Systems, vol. 64, no. 4, pp. 204-215. April 2021. DOI: 10.3103/S073527272104004X.

[62] A. Kosogor and Yu. Tikhov, "Rectangular- versus sine-corrugated waveguide polarizers for Ka-band gyro-TWT", 2019 International Vacuum Electronics Conference (IVEC), Busan, South Korea, 2019. DOI: 10.1109/IVEC.2019.8745028.

[63] B. Subbarao and V. F. Fusco, "Compact coaxial-fed CP polarizer", IEEE Antennas and Wireless Propagation Letters, vol. 3, pp. 145-147, April 2004. DOI: 10.1109/LAWP.2004.831084.

[64] R. Lech and J. Mazur, "Propagation in rectangular waveguides periodically loaded with cylindrical posts," IEEE Microwave and Wireless Components Letters, vol. 14, no. 4, pp. 177-179, 2004. DOI: 10.1109/LMWC.2004.827106.

[65] Q. C. Zhu, A. G. Williamson, and M. J. Neve, "Reactance of posts in circular waveguide", IEEE Transactions on Microwave Theory and Techniques, vol. 55, no. 8, pp. 1685-1688, August 2007. DOI: 10.1109/TMTT.2007.901605.

[66] K. Sellal, L. Talbi, T.A. Denidni, and J. Lebel "Design and implementation of a substrate integrated waveguide phase shifter," IET Microwaves, Antennas \& Propagation, vol. 2, no. 2, pp. 194-199, 2008. DOI: 10.1049/iet-map:20070135.

[67] S. B. Sharma, V. K. Singh, R. Dey, and S. Chakrabarty, "Analysis of a post discontinuity in an oversized circular waveguide," IEEE Transactions on Microwave Theory and Techniques, vol. 57, no. 8, pp. 1989-1995, 2009. DOI: 10.1109/TMTT.2009.2025448.

[68] J. Roelvink and A. G. Williamson, "Three transverse cylindrical posts in a rectangular waveguide," IEEE Microwave and Wireless Components Letters, vol. 20, no. 5, pp. 253-255, 2010. DOI: 10.1109/LMWC.2010.2045578.

[69] L. Polo-Lopez, J. L. Masa-Campos, and J. A. Ruiz-Cruz, "Design of a reconfigurable rectangular waveguide phase shifter with metallic posts," European Microwave Conference, Nuremberg, Germany, October 2017. DOI: 10.23919/EuMC.2017.8231036.

[70] A. V. Bulashenko, S. I. Piltyay, H. S. Kushnir and O. V. Bulashenko, "Compact waveguide polarizer with three antiphase posts", Visnyk of Vinnytsia Polytechnical Institute, no. 5, pp. 97-104, November 2020. (in Ukrainian). DOI: 10.31649/1997-9266-2020-152-5-97-104.

[71] J. A. Ruiz-Cruz, M. M. Fahmi, M. Daneshmand, and R. R. Mansour, "Compact reconfigurable waveguide circular polarizer," IEEE Microwave Symposium Digest (MTT), Baltimore, USA, June 2011, pp. 1-4. DOI: 10.1109/MWSYM.2011.5972872.

[72] J. Kim, S. Yoon, E. Jung, J. W. Lee, T. K. Lee, and W. K. Lee, "Triangular-shaped stepped septum polarizer for satellite communication," IEEE International Symposium on Antennas and Propagation (APSURSI), Spokane, USA, August 2011, pp. 854-857. DOI: 10.1109/APS.2011.5996409.

[73] W. Zhong, B. Li, Q. Fan, and Z. Shen, "X-band Compact Septum Polarizer Design," IEEE International Conference on Microwave Technology and Computational Electromagnetics (ICMTCE), Beijing, China, May 2011, pp. 167-170. DOI: 10.1109/ICMTCE.2011.5915191.

[74] C. A. Leal-Sevillano, K. B. Cooper, J. A. Ruiz-Cruz, J. R. Montejo-Garai, and J. M. Rebollar, “A 225 GHz circular polarization waveguide duplexer based on a septum orthomode transducer polarizer," IEEE Transactions on Terahertz Science and Technology, vol. 3, no. 5, pp. 574-583, September 2013. DOI: 10.1109/TTHZ.2013.2264317.

[75] J.-C. Angevain, and N. J. G. Fonseca, "Waveguide septum polarizer shaped with Legendre polynomials," 11th European Conference on Antennas and Propagation (EUCAP), Paris, France, March 2017, pp. 2286-2290. DOI: 10.23919/EuCAP.2017.7928324. 
Journal of Microwaves, Optoelectronics and Electromagnetic Applications, Vol. 20, No. 3, September 2021

DOI: http://dx.doi.org/10.1590/2179-10742021v20i31183

[76] N. Nikolic, A. Weily, I. Kekic, S. L. Smith, and K. W. Smart, "A septum polarizer with integrated square to circular tapered waveguide transition", IEEE International Symposium on Antennas and Propagation \& USNC/URSI National Radio Science Meeting, Boston, USA, July 2018, pp. 725-726. DOI: 10.1109/APUSNCURSINRSM.2018.8608909.

[77] B. Deutschmann and A. F. Jacob, "Broadband septum polarizer with triangular common port," IEEE Transactions on Microwave Theory and Techniques, vol. 68, no. 2, pp. 693-700, 2020. DOI: 10.1109/TMTT.2019.2951138.

[78] S. Piltyay, A. Bulashenko, O. Sushko, O. Bulashenko, and I. Demchenko, "Analytical modeling and optimization of new Ku-band tunable square waveguide iris-post polarizer", International Journal of Numerical Modelling: Electronic Networks, Devices and Fields, vol. 34, no. 5, pp. 1-27, 2021. DOI: 10.1002/JNM.2890.

[79] A. Bulashenko, S. Piltyay, Ye. Kalinichenko, and O. Bulashenko, "Mathematical modeling of iris-post sections for waveguide filters, phase shifters and polarizers", IEEE 2nd International Conference on Advanced Trends in Information Theory (ATIT), Kyiv, Ukraine, November 2020, pp. 330-336. DOI: 10.1109/ATIT50783.2020.9349321.

[80] S. Piltyay, A. Bulashenko, H. Kushnir, and O. Bulashenko, "New tunable iris-post square waveguide polarizers for satellite information systems", IEEE 2nd International Conference on Advanced Trends in Information Theory (ATIT), Kyiv, Ukraine, November 2020, pp. 342-348. DOI: 10.1109/ATIT50783.2020.9349357.

[81] S. Piltyay, A. Bulashenko, Ye. Herhil, and O. Bulashenko, "FDTD and FEM simulation of microwave waveguide polarizers", IEEE 2nd International Conference on Advanced Trends in Information Theory (ATIT), Kyiv, Ukraine, November 2020, pp. 357-363. DOI: 10.1109/ATIT50783.2020.9349339.

[82] S. I. Piltyay, A. V. Bulashenko, and Y. Y. Herhil, "Numerical performance of FEM and FDTD methods for the simulation of waveguide polarizers", Visnyk NTUU KPI Seriia - Radiotekhnika, Radioaparatobuduvannia, vol. 84, pp. 11-21, March 2021. DOI: 10.20535/RADAP.2021.84.11-21. 